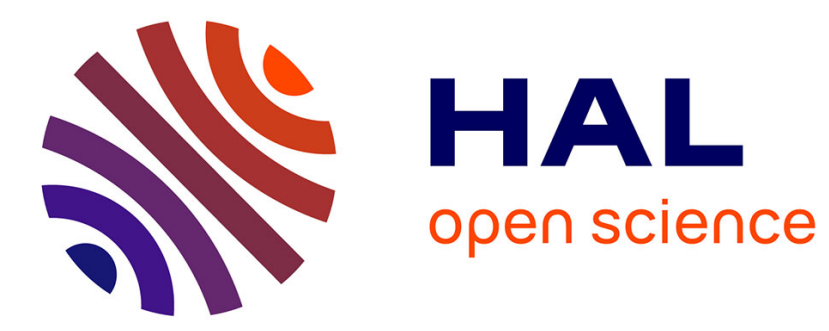

\title{
THE STATIC AND DYNAMIC STRUCTURE FACTOR OF EXPANDED LIQUID ALKALI METALS
}

\author{
R. Winter, C. Pilgrim, F. Hensel
}

\section{To cite this version:}

R. Winter, C. Pilgrim, F. Hensel. THE STATIC AND DYNAMIC STRUCTURE FACTOR OF EXPANDED LIQUID ALKALI METALS. Journal de Physique IV Proceedings, 1991, 01 (C5), pp.C545-C5-50. 10.1051/jp4:1991505 . jpa-00250629

\section{HAL Id: jpa-00250629 https://hal.science/jpa-00250629}

Submitted on 1 Jan 1991

HAL is a multi-disciplinary open access archive for the deposit and dissemination of scientific research documents, whether they are published or not. The documents may come from teaching and research institutions in France or abroad, or from public or private research centers.
L'archive ouverte pluridisciplinaire HAL, est destinée au dépôt et à la diffusion de documents scientifiques de niveau recherche, publiés ou non, émanant des établissements d'enseignement et de recherche français ou étrangers, des laboratoires publics ou privés. 


\title{
THE STATIC AND DYNAMIC STRUCTURE FACTOR OF EXPANDED LIQUID ALKALI METALS
}

\author{
R. WINTER, C. PILGRIM and F. HENSEL \\ Institute of Physical Chemistry and Materials Science Center, Philipps University of Marburg, D-3550 \\ Marburg, Germany
}

\begin{abstract}
We present results from neutron diffraction experiments on liquid rubidium and cesium from their melting point up to their liquid-vapour critical point. Near their critical point, the change from a liquid metal to a nonmetal takes place. The characteristic changes of the electronic properties and of the microscopic structure, such as the mean distance and number of nearest neighbours, which occur during the expansion of the liquid metals, are discussed. By inelastic neutron scattering, also the coherent dynamic structure factor $S(Q, \omega)$ of expanded liquid rubidium has been measured up to $1700 \mathrm{~K}$ at conditions close to the liquid-vapour coexistence curve. The existence of collective density excitations at short wavelength and high frequency for the expanded liquid metal is discussed and the Enskog self-diffusion coefficient is evaluated from the experimental data.
\end{abstract}

\section{Introduction}

The main interest in the study of expanded liquid alkali metals like $\mathrm{Rb}$ and $\mathrm{Cs}$ is to find out how the structure, dynamics and effective interaction potential change during the expansion of the liquid metals from their melting point towards their liquid-vapour critical point (critical data for $\mathrm{Rb}: \mathrm{T}_{\mathrm{c}}=2017 \mathrm{~K}, \mathrm{P}_{\mathrm{c}}=124$ bar, $\mathrm{d}_{\mathrm{c}}=0.29 \mathrm{gcm}^{-3}$; for Cs: $\mathrm{T}_{\mathrm{c}}=1924 \mathrm{~K}$, $P_{c}=92$ bar, $\left.d_{c}=0.38 \mathrm{gcm}^{-3} / 1 /\right)$. Near their critical point, the change from a liquid metal to a nonmetal takes place, as can be infered from measurements of the electrical conductivity, magnetic susceptibility and optical reflectivity $/ 1-4 /$. The occurance of the metal-nonmetal transition implies that the interatomic forces must exhibit drastic changes when the liquid is expanded and the critical point is approached. In this paper, we present results from elastic and inelastic neutron scattering experiments, revealing how the structure, interatomic forces and dynamical properties change during the expansion of liquid alkali metals. The experiments were performed at the Institut Laue-Langevin in Grenoble, using the diffractometer $\mathrm{D} 4 \mathrm{~B}(\lambda=0.7 \AA)$ for measurements of $\mathrm{S}(\mathrm{Q})$ and the TOF-spectrometer IN6 $\left(\mathrm{E}_{0}=4.81 \mathrm{meV}\right)$ for measurements of $\mathrm{S}(\mathrm{Q}, \omega)$. The high-temperature, high-pressure sample environment necessary for these measurements was achieved within an internally heated pressure vessel. Details of the experimental setup and data analysis are described in $/ 5,6 /$. 


\section{Results and Discussion}

As an example, Figure 1 shows selected results for the pair correlation function $g(R)$ of expanded liquid cesium - which has been obtained by Fourier transformation of the measured static structure factor $S(Q)$ - from the melting point up to nearly its critical point $/ 7,8 /$. A continuous smearing out of the liquid structure is observed during the expansion of the liquid metal. From $g(R)$, the mean distance $R_{1}$ and number $N_{1}$ of nearest neighbours have been obtained, as shown in Figure $2 . \mathrm{N}_{1}$ decreases linearly with decreasing density, whereas the distance of nearest neighbours is almost unchanged during the expansion of the liquid metals $\mathrm{Cs}$ and $\mathrm{Rb} / 7-10 /$. The dominant effect on the properties of the expanded liquid alkali metals thus derives from a reduced number of nearest neighbours and not from a drastic change of the mean interparticle distance. From additional measurements of the isothermal pressure derivative of $S(Q)$ over the whole liquid range of liquid $\mathrm{Cs}$, valuable information about three-body correlations and the validity of model potentials could be obtained $/ 8,9 /$. The observed structural changes also allow the test of models for electronic properties, such as the nearly-free electron model (NFE), of the expanded metal $/ 7,8 /$. The results show that the validity of the NFE-model fails already at relatively high densities of about three times the critical density. The region of densities where these changes occur is the same as that in which magnetic $/ 3,4 /$, optical data /1/ and thermodynamic perturbation theories /11/ indicate the presence of many-body correlation effects, which are the precursors of the metal-nonmetal transition, which finally takes place near the liquid-vapour critical point. As can be revealed from measurements of the magnetic susceptibility /3,4/ and from quantum statistical calculations $/ 12 /$, localized spezies, such as Cs atoms and dimers, are formed near the critical point.

In order to obtain also information about dynamical properties of the expanded liquid metals, such as the self-diffusion coefficient and collective excitations, the dynamic structure factor $\mathrm{S}(\mathrm{Q}, \omega)$ of liquid $\mathrm{Rb}$ has been measured up to $1673 \mathrm{~K}$. As known for long, and in contrast to results on dense Lennard-Jones systems, liquid alkali metals near their melting point exhibit distinct longitudinal collective excitations in a large region of the $\mathrm{Q}-\omega$-space $/ 13,14 /$. As far as liquid $\mathrm{Rb}$ and liquid $\mathrm{Cs}$ at the melting point are concerned, these phonon-like collective modes have been observed as side peaks or shoulders in a range of wave numbers $Q$ far outside the hydrodynamic region $/ 13,14 /$. The presence of such a mode for a liquid metal, and its absence in inert gas liquids, can be attributed to the special shape of the effective interaction potential of the fluid metal /15/.

As an example, Figure 3 exhibits plots of $S(Q, \omega)$ at $T=1373 \mathrm{~K}$ for some selected $Q-$ values. Broad shoulders around the central peak of $S(Q, \omega)$ are still indicated at Q-values around $1 \AA^{-1}$, i.e. the sound mode excitations can still be seen at this high temperature, though they are highly damped. Around $Q_{0}-$ the position of the first maximum of $S(Q)$, which occurs around $1.5 \AA^{-1}$ - the de Gennes narrowing /16/ is observed, and beyond $Q_{0}$, again a shoulder appears to grow out of the central peak. A similar behaviour has been observed for $\mathrm{S}(\mathrm{Q}, \omega)$ at $\mathrm{T}=1073 \mathrm{~K}$ and $\mathrm{T}=1673 \mathrm{~K}$.

In Figure 4, the corresponding dispersion relation $\hbar \omega_{\mathrm{m}}(\mathrm{Q})$ for the collective excitations, as 


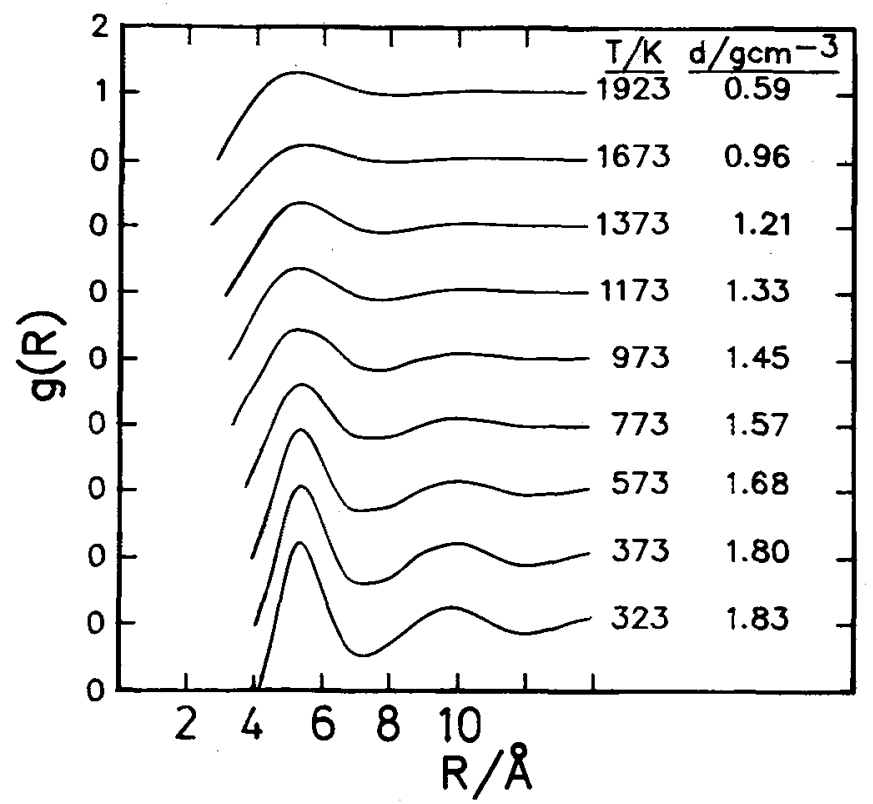

Fig. 1 Pair correlation function $g(R)$ of expanded liquid Cs.

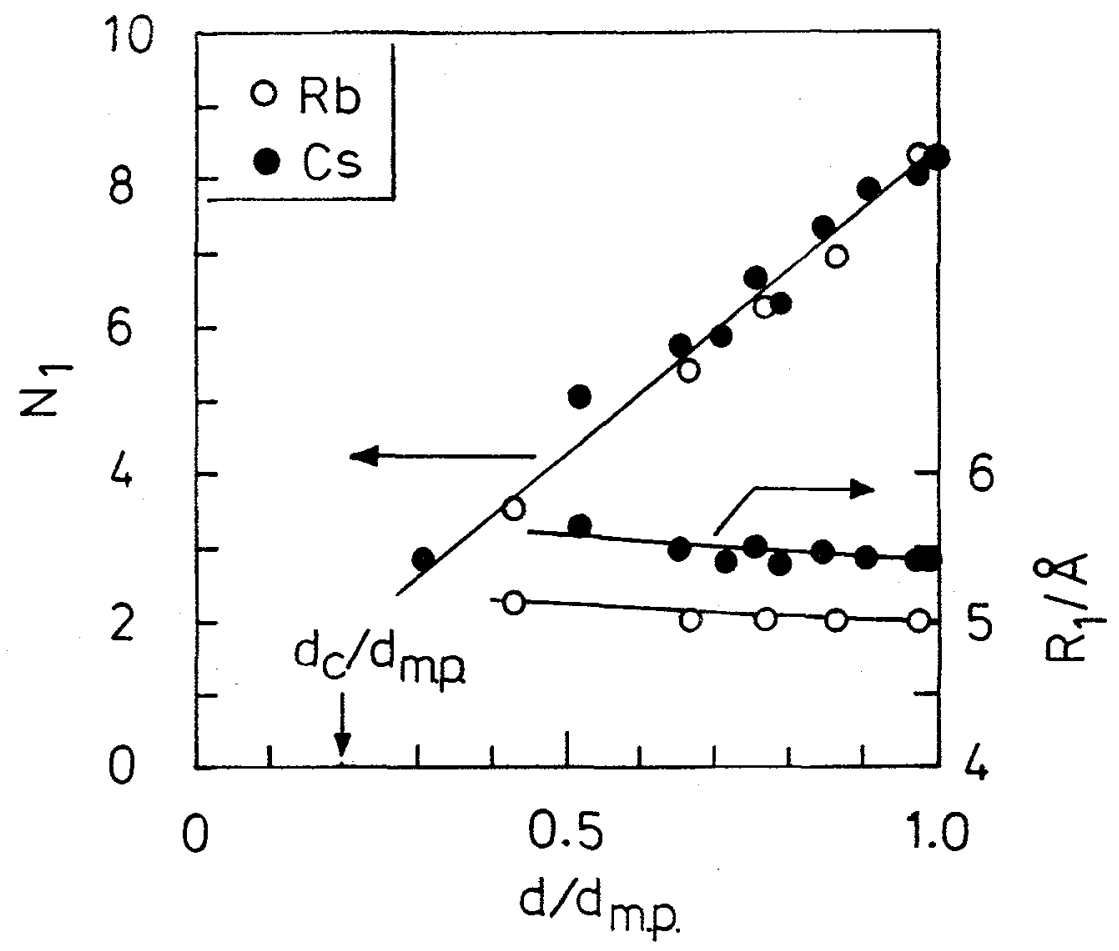

Fig. 2 Mean number $\mathrm{N}_{1}$ and distance $\mathrm{R}_{1}$ of nearest neighbours of expanded liquid $\mathrm{Cs}$ and $\mathrm{Rb}$ (the densities are normalized to the values at the melting point, $\mathrm{d}_{\mathrm{m} . \mathrm{p} \text {. }}$ ). 


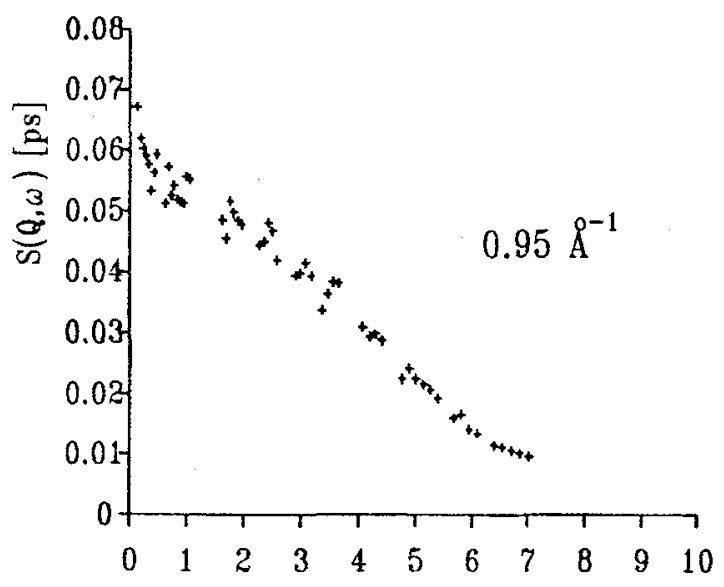

$\hbar \omega[\mathrm{meV}]$

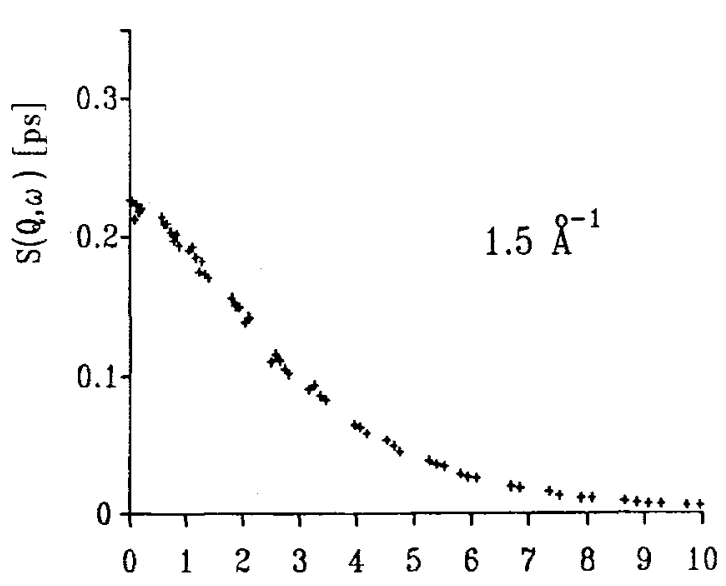

$\hbar \omega[\mathrm{meV}]$
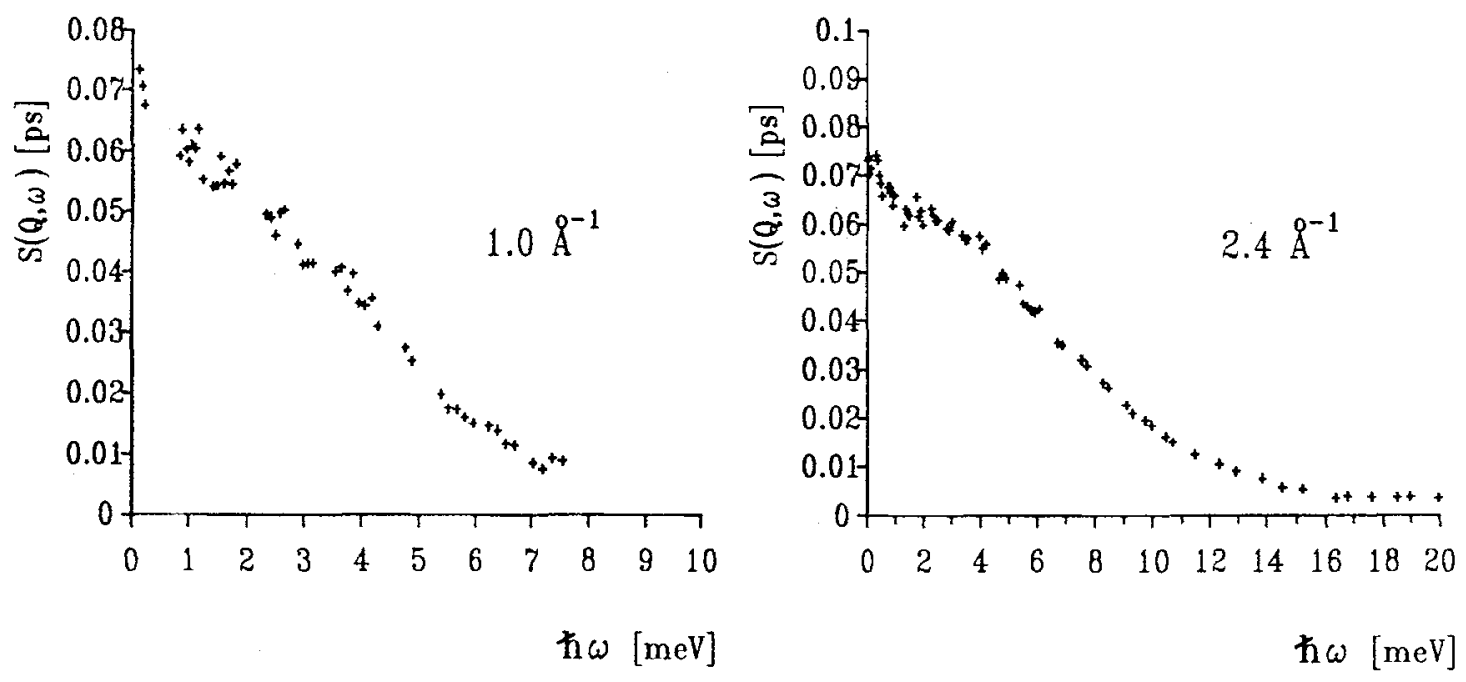

Fig. 3 Plots of the dynamic structure factor $S(Q, \omega)$ of expanded liquid $R b$ at $T=1373$ $\mathrm{K}$ for selected Q-values.

evaluated from the longitudinal density current correlation function $J_{1}(Q, \omega)=\omega^{2} S(Q, \omega) / Q^{2}$ (eq. 1), is shown for these temperatures. For comparison, the corresponding data of Copley and Rowe for $\mathrm{Rb}$ at $320 \mathrm{~K} / 13 /$ are included. It is seen, that the maximum energy of the dispersion relation of about $5 \mathrm{meV}$ for $\mathrm{Q}<\mathrm{Q}_{0}$ is similar for all temperatures. This indicates that at these measured conditions of temperature and density, i.e. up to about three times the critical density, the collective ion-ion dynamics is still controlled by the "electron sea" of the expanded liquid metal. A more detailed quantitative analysis of the form of $S(Q, \omega)$ and the dispersion relation in terms of a complex memory function $M(Q, t)$ will be performed in the future. 


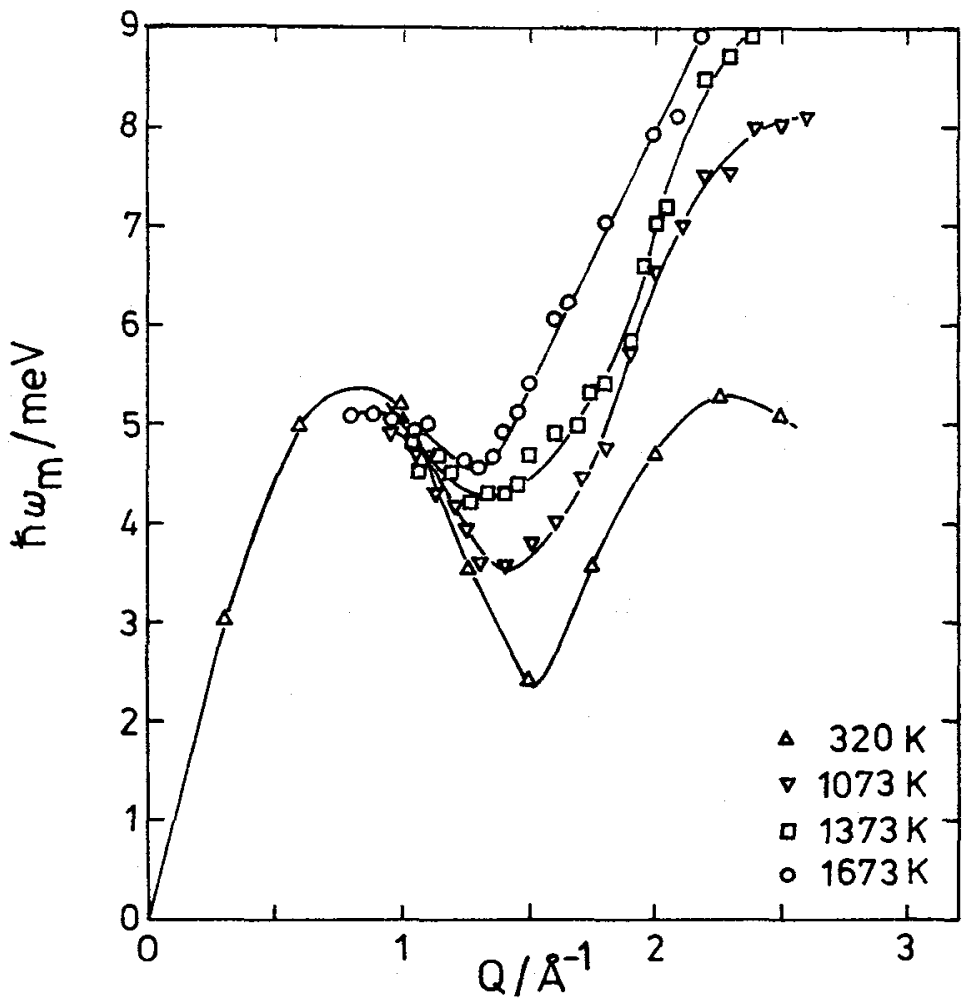

Fig. 4 The dispersion relation $\hbar \omega_{m}(Q)$ - as obtained from the maximum of the current density correlation function - of liquid $\mathrm{Rb}$ at several temperatures $(\Delta 320 \mathrm{~K}$ $/ 13 /, \nabla 1073 \mathrm{~K}, \mathrm{Q} \quad 1373 \mathrm{~K}, \mathrm{o} 1673 \mathrm{~K})$.

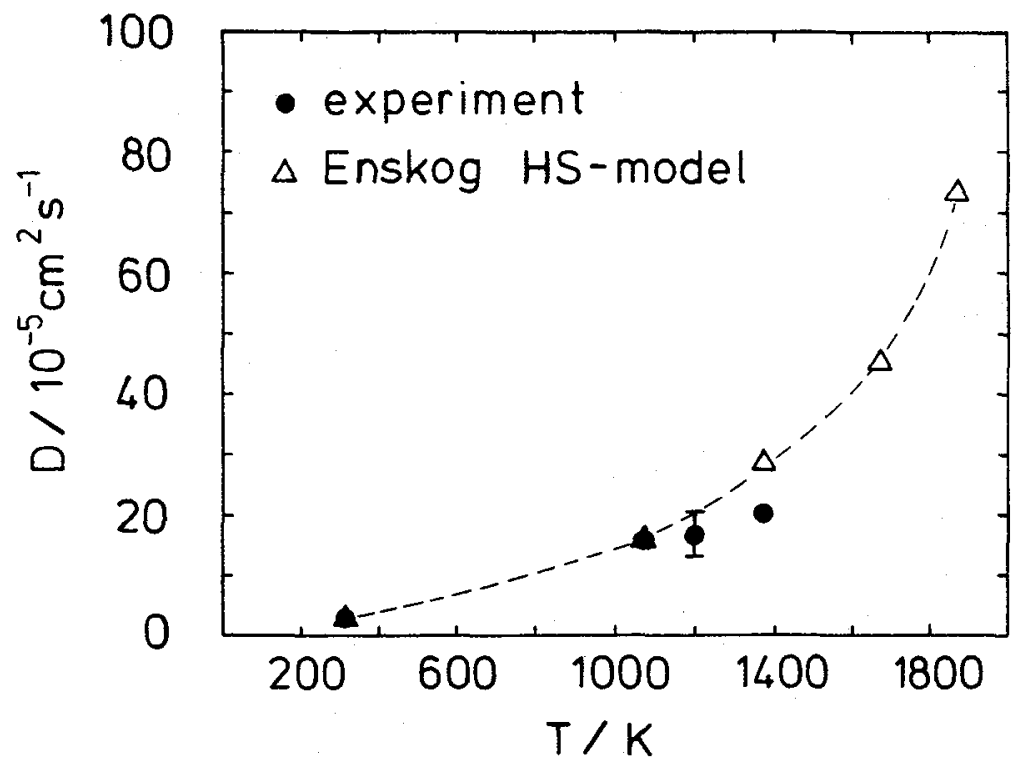

Fig. 5 Self-diffusion coefficient $D_{E}(\bullet)$ of expanded liquid $R b$ and comparison with a hard-sphere fluid $(\Delta)$. 
Following recent theoretical results $/ 17 /$, the coherent central half width $\omega_{1 / 2}(\mathrm{Q})$ of $S(Q, \omega)$ in the vicinity of the structure factor maximum $S\left(Q_{0}\right)$ can be described in good approximation by $\omega_{1 / 2}(\mathrm{Q})=\mathrm{D}_{\mathrm{E}} \mathrm{Q}^{2} \mathrm{~d}(\mathrm{Q}) / \mathrm{S}(\mathrm{Q})$ (eq. 2), with $\mathrm{D}_{\mathrm{E}}$ the Enskog self-diffusion coefficient $\left(\mathrm{d}(\mathrm{Q})\right.$ contains spherical Bessel functions $\mathrm{j}_{\mathrm{n}}(\mathrm{Q} \sigma) ; \sigma$ hard-core diameter). This equation is valid for about $Q_{0} 1 \leq 1$ ( 1 mean free path),i.e. up to a maximum temperature of about $1400 \mathrm{~K}$. In Figure $5, \mathrm{D}_{\mathrm{E}}$ as obtained from eq. 2 is shown in comparison to the self-diffusion coefficient of the simple Enskog hard-sphere model, $\mathrm{D}_{\mathrm{HS}}=\left(3 / 8 \mathrm{n} \sigma^{2} \mathrm{~g}(\sigma)\right)\left(\mathrm{k}_{\mathrm{B}} \mathrm{T} / \pi \mathrm{m}\right)^{1 / 2}$ (eq. 3 ), which considers uncorrelated binary collisions only /18/. The temperature dependent hard-core diameter $\sigma(\mathrm{T})$ has been obtained by fitting the hard-sphere model in the Percus-Yevick approximation $/ 19 /$ to the experimentally obtained first maximum of $S(Q)$. Good agreement has been obtained for $\mathrm{D}_{\mathrm{HS}}$ with experimental values at the melting point /20,21/. As can be clearly seen, up to $1200 \mathrm{~K}$ the experimentally obtained self-diffusion coefficient $\mathrm{D}_{\mathrm{E}}$ of the expanded fluid metal is similar to that of a hard-sphere fluid with an effective hard-core diameter $\sigma(\mathrm{T})$ derived from $S\left(Q_{0}\right)$. Around $1400 \mathrm{~K}$, small deviations are observed, which could be due to the limited validity of eq. 2 , however.

\section{References}

/1/ HENSEL, F, J. Non-Cryst. Solids 117/118 (1990) 441

12/ FREYLAND, $W$ and HENSEL, F, in "The Metallic and Nonmetallic States of Matter" (eds. Edwards, P P and Rao, C N R), Taylor \& Francis, London, 1985

/3/ FREYLAND, W, Phys. Rev. B. 20 (1979) 5104

14/ HANANY, W El, BRENNERT, G F and WARREN, W W, Phys. Rev. Lett. 50 (1983) 540

/5/ WINTER, R and BODENSTEINER, T, High Pressure Research 1 (1989) 23

/6/ BODENSTEINER, T, PhD-thesis, TU München, 1990

17) WINTER, R, BODENSTEINER, T, GLÄSER, W and HENSEL, F, Ber. Bunsenges. Phys. Chem. 91 (1987) 1327

/8/ WINTER, $R$ and HENSEL, F, Phys. Chem. Liq. 20 (1989) 1

/9/ WINTER, $R$, HENSEL, F, BODENSTEINER, T and GLÁSER, W, J. Phys. Chem. $92(1988) 7171$

/10/ FRANZ, G, FREYLAND, W, GLÄSER, W, HENSEL, F and SCHNEIDER E, J. de Physique Coll. 41 (1980) C8-194

/11/ KAHL, G and HAFNER, J, J. Phys. Rev. A 29 (1984) 3310

112/ REDMER, R and RÖPKE, G, Contrib. Plasma Phys. 29 (1989) 4/5, 343

113/ COPLEY, J R D and ROWE, M, Phys. Rev. Lett. 32 (1974) 49

/14/ BODENSTEINER, T, MORKEL, C, MÜLLER, $P$ and GLÄSER, W, J. Non-Cryst. Solids 118 (1990a) 116

/15/ RAHMAN, A, Phys. Rev. A 9 (1974) 1667

16/ De GENNES, P G, Physica 25 (1959) 825

117) COHEN, E G D, WESTERHUIJS, P, and De SCHEPPER, I M, Phys Rev. Lett. 59 (1987) 2872

/18/ see e.g. GERL, M, in "Amorphous Solids and the Liquid State" (eds. March, N H, Street, $R$ A and Tosi, M), Plenum Press, New York, 1985

/19/ see e.g. SHIMOJI, M "Liquid Metals", Academic Press, London, 1977

/20/ OHSE, R W, "Handbook of Thermodynamic and Transport Properties of Alkali Metals", Blackwell Scientific Publications, London, 1985

/21/ TANAKA, M, J. Pys. F 10 (1980) 2581 and ref. therein 